\title{
Oral squamous cell carcinoma: Review of prognostic and predictive factors
}

\author{
João Massano, MD, ${ }^{a}$ Frederico S. Regateiro, MD, ${ }^{\mathrm{b}}$ Gustavo Januário, MD, ${ }^{\mathrm{c}}$ \\ and Artur Ferreira, MD, ${ }^{\mathrm{d}}$ Coimbra, Portugal \\ UNIVERSITY OF COIMBRA AND COIMBRA UNIVERSITY HOSPITAL
}

\begin{abstract}
Oral squamous cell carcinoma has a remarkable incidence worldwide and a fairly onerous prognosis, encouraging further research on factors that might modify disease outcome. In this review article, the authors approach the factors that may exert influence on the prognosis and eventually guide the selection of patients for more aggressive therapies. Published scientific data was collected, selected, and grouped into 3 main clusters: patient-, tumor-, and treatment-related factors. Well established aspects are discussed, but also those less common or with only supposed usefulness. Disease staging, extracapsular dissemination, resection margin free of disease, and tumor thickness are factors with high influence on the prognosis. There has been an increasing interest in the study of tumor molecular factors, and some have been strongly correlated with the outcome, showing promising pathways for the future development of more effective prognosis systems and anticancer therapies.
\end{abstract}

(Oral Surg Oral Med Oral Pathol Oral Radiol Endod 2006;102:67-76)

Squamous cell carcinomas (SCC, Fig. 1) encompass at least $90 \%$ of all oral malignancies. ${ }^{1,2}$ Oral cancer holds the eighth position in the cancer incidence ranking worldwide, with epidemiologic variations between different geographic regions (it is the third most common malignancy in south-central Asia). ${ }^{3}$ The World Health Organization expects a worldwide rising oral squamous cell carcinomas (OSCC) incidence in the next decades. In the US, OSCC represents $2 \%-4 \%$ of the annually diagnosed malignancies, being responsible for 8,000 deaths every year. ${ }^{4,5}$ In the US, at the time of diagnosis, $36 \%$ of patients have localized disease, $43 \%$ regionally spread disease, and $9 \%$ present distant metastasis. ${ }^{4}$ In some western European countries, such as Belgium, Denmark, Greece, Portugal, and Scotland, there has been an upward trend in the incidence of OSCC. Increasing mortality rates have been observed for at least $2 \mathrm{de}$ cades in Eastern Europe, where OSCC comprises a real public health issue. ${ }^{6}$ OSCC implies quite significant mortality and morbidity rates, ${ }^{1,2,4,5}$ and in spite of the vast amount of research and the advances accomplished in the field of oncology and surgery, the mortality rates remain unchanged. This motivates the search of factors with prognostic relevance in order to better tailor the

\footnotetext{
${ }^{\mathrm{a}}$ Faculty of Medicine, University of Coimbra; Coimbra University Hospital, Coimbra, Portugal.

${ }^{\mathrm{b}}$ Faculty of Medicine, University of Coimbra, Coimbra, Portugal.

${ }^{\mathrm{c}}$ Faculty of Medicine, University of Coimbra; Coimbra University Hospital, Coimbra, Portugal.

${ }^{\mathrm{d} D e p a r t m e n t}$ of Maxillofacial Surgery, Coimbra University Hospital, Coimbra, Portugal.

Received for publication Apr 8, 2005; returned for revision Jul 22, 2005; accepted for publication Jul 28, 2005.

$1079-2104 / \$$ - see front matter

(c) 2006 Mosby, Inc. All rights reserved.

doi:10.1016/j.tripleo.2005.07.038
}

individual management of OSCC patients. The purpose of this article is to list and discuss some of these factors, focusing also on some of the most promising.

\section{METHODS}

A web-based search for all types of articles published was initiated using MEDLINE/PubMed, with the key words "oral," "cancer," and "prognosis." The search was subsequently refined. The sites of specialized scientific journals in the areas of oral and maxillofacial surgery, oral medicine, and oncology were also used. In order to achieve a concise and informative text all authors were engaged in the selection of the information to be used, first on an individual basis and the final choice accomplished by group consensus. We have subsequently devised a wide-ranging selection of factors with potential influence on the outcome of this disease, whether well established ones or more recent with only conjectural usefulness. No additional statistical analysis has been conducted. Three clusters of issues were formulated: patient-, tumor-, and treatment-related factors.

\section{REVIEW OF THE LITERATURE Patient-related factors}

Sex and age. Apparently, there are no prognostic differences between males and females, ${ }^{7-9}$ although some authors have reported lower survival rates in females, attributed to delay in seeking medical care and lower acceptance of treatment. ${ }^{10}$ The correlation of prognosis with age seems controversial, and some authors show no relationship between them, ${ }^{7-9,11}$ whereas others demonstrate worse prognosis in older patients. ${ }^{10,12}$

Tobacco and alcohol. Although some results deny any association between survival and smoked tobacco or alcohol consumption, ${ }^{7}$ most authors report higher mortality in smokers and alcohol drinkers. ${ }^{10,12,13}$ Betel 


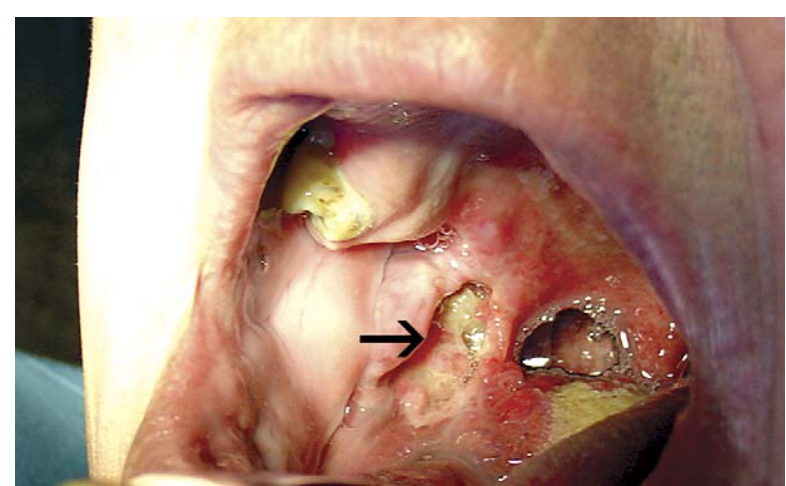

Fig. 1. Squamous cell carcinoma of the retromolar trigone, presenting as an ulcerated lesion (photograph taken with the patient's consent).

quid chewing (a common habit in some regions of Asia and some Asian communities in the western world) has been specifically correlated with poorer prognosis. ${ }^{7}$ Smokers and alcohol drinkers seem to be at higher risk for the development of second primary oral cancer than nonsmokers and nondrinkers, thus facing more onerous outcomes. ${ }^{14-17}$ This is also the case for those who maintain tobacco and alcohol consumption following diagnosis of the primary tumor. ${ }^{15-18}$ Clinicians should therefore make every effort to persuade all patients (including those already treated for OSCC) to abandon these detrimental habits.

Socioeconomic conditions. Apparently, the outcome is somewhat worse for patients with lower socioeconomic status and education, most likely because of poorer oral hygiene and more difficult access to medical care. ${ }^{10}$

Diagnostic delays. It seems highly likely that diagnostic delays raise the probability of higher tumor growth and spread, consequently aggravating the prognosis. However, an extensive review concerning OSCC pointed out that the available data fail to demonstrate this thesis, ${ }^{19}$ a fact partially attributed to methodologic insufficiencies of the published studies. Another possible theory is that patients with more hostile tumors develop symptoms earlier, seeking medical attention sooner; nevertheless, these patients still have to face a more grievous outcome, because these malignancies display a more aggressive biologic behavior.

Miscellaneous. Comorbid conditions may worsen disease outcome as a consequence of increased organic stress afflicting the patient. ${ }^{12,13,20}$ Survival rates are lower in patients with concomitant OSCC and disorders such as congestive heart failure, arrhythmias, peripheral vascular disease, pulmonary and renal diseases, and other cancers, either treated or untreated. ${ }^{20}$ Depressed host immune status seems to play an adverse role on survival of patients with oral cancer. Patients under immunosuppressive therapy following solid organ transplant

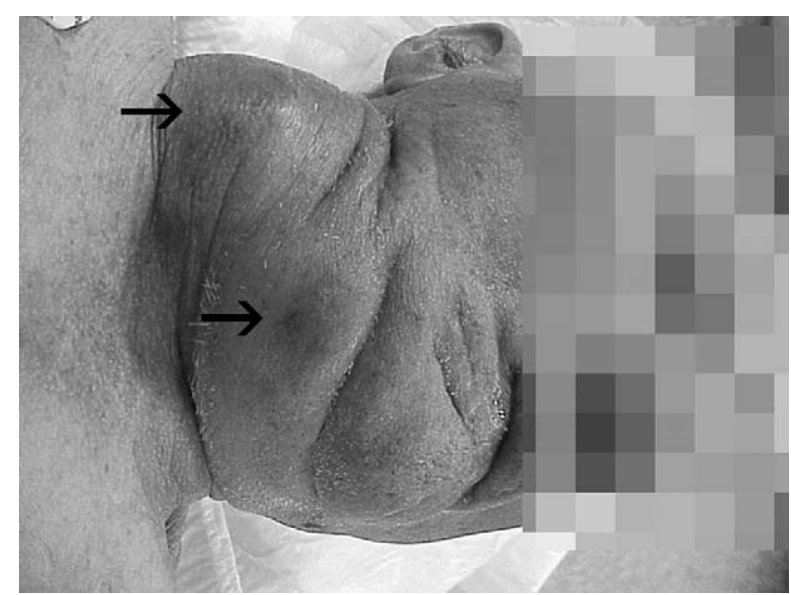

Fig. 2. Exuberant late cervical metastases from previously treated squamous cell carcinoma of the inferior lip (photograph taken with the patient's consent).

who developed OSCC fare worse than individuals with a less depressed immune system. ${ }^{21}$ Additionally, there is an association between lower 5-year survival rates in patients with OSCC and evidence of immune depression. ${ }^{22}$ These facts highlight the importance of immune response in tumor control and the potential value of cancer immunotherapy. ${ }^{22,23}$ Some specific symptoms, such as odynophagia, oral abnormal hemorrhage, and weight loss, also have been correlated with shorter survival. ${ }^{12}$ Weight loss is associated with higher mortality rates in patients with OSCC with recurrence or persistence of disease, or second primary tumor. ${ }^{9}$

\section{Tumor-related factors}

Anatomic site. Vascular and lymphatic networks, which vary between different anatomic sites, may influence tumor evolution and the outcome. Higher metastatic disease rates for SCC at the base rather than at the oral tongue have been reported. ${ }^{24}$ Leite and Koifman ${ }^{10}$ showed higher mortality rates in patients with tongue carcinomas than in those who developed lip carcinomas. In addition, some anatomic sites are linked with poorer outcome owing to the rich lymphatic drainage and the local extension being hard to evaluate and manage, such as the superior gingivolabial sulcus. $^{25}$

Disease staging. Cancer staging is based on the TNM system, which has been labeled as imperfect, per se, for prognostic purposes. ${ }^{8,9,12,13,26-30}$ However, the vast majority of authors accepts that disease staging has a crucial influence on the outcome. Guerra et al. ${ }^{31}$ reported 5 -year survival rates of $82 \%$ for initial stages and $49 \%$ for advanced disease. Lo et al. ${ }^{7}$ described 5-year survival rates of $75 \%, 65.6 \%, 49 \%$, and $30 \%$ for disease stages I, II, III, and IV, respectively. Gonzales-Moles et al. ${ }^{26}$ 
showed categorical influence of parameters $\mathrm{T}$, patho$\operatorname{logic} \mathrm{T}, \mathrm{N}$, and pathologic $\mathrm{N}$ on the vital prognosis. Nguyen and Yueh ${ }^{9}$ found 1-year survival rates of $60 \%$ (stage I) and 32\% (stage IV) in patients with recurrence, persistent disease, or second primary cancer.

Cervical node metastases (Fig. 2) have variable incidence and are widely accepted as one of the major prognostic factors in patients with OSCC. ${ }^{32-35}$ Their presence is associated with a decrease in global survival to roughly half as well as with higher recurrence rates. ${ }^{24,34-36}$ Cervical node metastases may be classified into 2 distinct categories: overt (clinical) or nonovert (occult). The latter may be further categorized as metastatic deposits detectable by traditional methods (staining with hematoxylin and eosin and observed with light microscopy) or "submicroscopic" metastases, only apparent after performing immunohistochemical or molecular analysis of the dissected lymph nodes. ${ }^{32}$ These techniques seem quite promising, given that in patients with no clinical or radiologic evidence of metastatic dissemination, occult node metastases were detected in $20 \%-40 \%$ of cases. ${ }^{36}$ A retrospective study involving 266 patients who had previously undergone surgery and cervical node dissection, revealed that $34 \%$ of those initially classified as $\mathrm{cN} 0 \mathrm{had}$, in fact, occult metastatic disease $(\mathrm{pN}+) .{ }^{33}$ Therefore, staging based on pathologic analysis following neck dissection should be considered, in order to identify high-risk patients who may benefit from adjuvant therapy, because those with node metastases show significantly lower survival rates than those with disease-free nodes. ${ }^{33,34}$

Tumor thickness. The risk of nodal metastases and mortality rates vary directly with the thickness of the primary tumor. ${ }^{8,11,26} \mathrm{O}$-charoenrat et al. found that tumor thickness above $5 \mathrm{~mm}$ is a strong predictor of occult nodal metastases and should indicate an elective neck dissection. ${ }^{8}$ There is evidence that tumor thickness may exercise more influence on the survival rates than factors such as clinical and pathologic staging. ${ }^{26}$

Extracapsular spread (ECS). Defined as extranodal extension of metastatic deposits outside the lymph node capsule (Fig. 3), ECS is a noticeably important prognostic factor, associated with higher locoregional recurrence rates, distant metastases, and lower survival rates. ${ }^{33,35,36}$ Some authors report a decrease in survival rates between $29 \%$ and $60 \%$, as well as an increase in nodal metastases rates, when ECS is observed ${ }^{34}$; others show 5-year survival rates of $21 \%$ in patients with ECS vs $64 \%$ for those with intranodal metastases. ${ }^{35} \mathrm{~A}$ descriptive evaluation system of ECS extension subdivides it into macro- and microscopic. ${ }^{36}$ Macroscopic ECS is evident to the naked eye, and microscopic ECS is only demonstrable during histologic analysis. By studying the cervical nodes of 173 patients diagnosed with
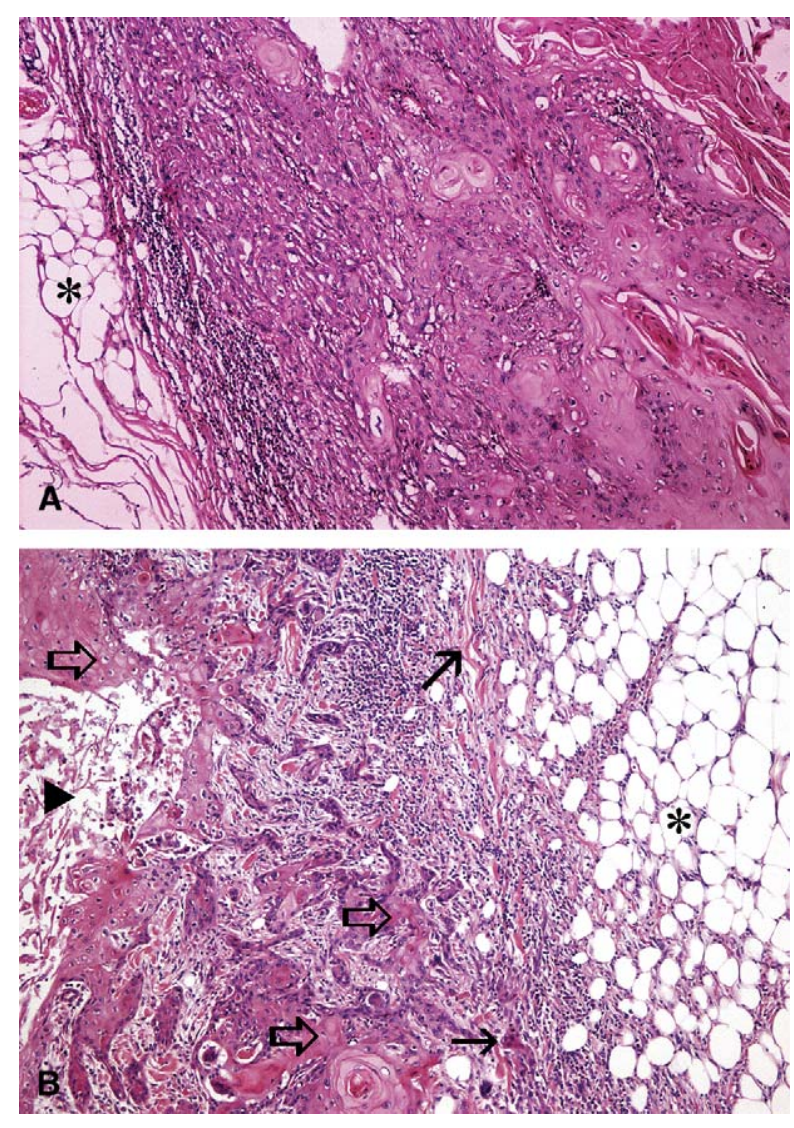

Fig. 3. A, Lymph node metastasis from well differentiated OSCC. There is lymph node capsule thinning and invasion (although not complete destruction). Asterisk marks perinodal fat tissue. H\&E, original magnification $\times 50$ (courtesy of Professor Silvério Cabrita, Department of Experimental Pathology, Faculty of Medicine, University of Coimbra, Portugal). B, Microscopic extracapsular spread, not detectable by macroscopic examination. Lymph node metastasis from well differentiated OSCC (thick arrows), with necrotic area shown (triangle). A cluster of cancer cells is shown (thin horizontal arrow), and what seem to be remnants of the lymph node capsule are still visible (thin oblique arrow). Asterisk marks perinodal fat tissue. H\&E, original magnification $\times 100$ (courtesy of Dr. Maria José Julião, Department of Pathology, Coimbra University Hospital, Portugal).

OSCC and histologically confirmed presence of nodal metastases, Woolgar et al. ${ }^{35}$ found that the 3 -year survival probability was similar in those with macroscopic or microscopic ECS (33\% and 36\%, respectively) and much worse than the rate of $72 \%$ for those with strict intranodal metastases. Additionally, it has been found that patients with multiple metastatic nodes have poorer prognosis, and individuals with multiple nodes with ECS show an extremely short median time interval until disease recurrence as well as higher mortality rates. ${ }^{36}$ These findings support the notion that these patients 
are at high risk for treatment failure, and are serious candidates for adjuvant treatment intensification. In a series of 266 patients treated surgically, with or without adjuvant radiotherapy, Greenberg et al. ${ }^{36}$ established the 5 -year disease-specific survival rates of $88 \%$ for those classified as $\mathrm{pN} 0,65 \%$ for patients $\mathrm{pN}+/ \mathrm{ECS}-$, and $48 \%$ for those $\mathrm{pN}+/ \mathrm{ECS}+$. Therefore, it seems important to integrate ECS into pathologic staging systems, including microscopic ECS. ${ }^{35}$ The additional costs would probably be low compared to the final benefits.

Histologic differentiation. Most authors have established significant correlations between lower histologic differentiation and poorer prognosis, ${ }^{7,9,20,27,37}$ but others did not find such association. ${ }^{8,10,11}$

Perineural invasion. Perineural invasion apparently correlates with higher probability of regional and distant metastases, higher depth of tumor invasion, lower differentiation, and lower 5-year survival rates in OSCC. ${ }^{38}$ Rodolico et al. ${ }^{39}$ showed that perineural invasion correlates with the risk of nodal metastases.

Angiogenesis. Malignancies have the ability to induce growth of new blood vessels, which is important for tumor progression, aggressiveness, and ability to metastasize. It is a highly regulated and complex process. ${ }^{40}$ Most authors assess tumor angiogenesis by counting the number of blood vessels (microvessel density, MVD) in tissue sections. Vessels are observed using several immunohistochemical staining techniques. ${ }^{41,42}$ Other methods have been developed to evaluate angiogenesis, such as the Chalkley method and flow cytometry vessel counting. ${ }^{41,42}$ Using the MVD technique, Shpitzer et al. ${ }^{28}$ have studied early-stage tongue SCC angiogenesis, reporting that it may be an important factor for tumor hostility. Marked angiogenesis correlated well with the risk of nodal metastases and should probably imply a more aggressive postoperative adjuvant therapy. Moreover, OSCC angiogenesis correlates with $\mathrm{T}$ and $\mathrm{N}$ parameters and is an independent predictor of tumor recurrence and a reliable prognosticator. ${ }^{29}$

The VEGF plays a decisive role in the development of blood vessels; it is a key component in tumor angiogenesis, and 4 subtypes have been described (A, B, C, and D). ${ }^{43,44}$ Shintani et al. ${ }^{43}$ recently described its expression in OSCC, correlating subtypes A and B with tumor angiogenesis and subtypes $\mathrm{C}$ and $\mathrm{D}$ with the risk of nodal metastases. The latter were also frequently upregulated in the invasive front of the tumor, indicating a possible role in the process of tumor invasion and development of metastases. Uehara et al. ${ }^{44}$ found a significant correlation between the high expression of VEGF in OSCC and worse prognosis.

Tumor expression of cyclooxygenase-2 (COX-2). Recently, a strong correlation was found in OSCC between high COX-2 expression and higher lymph node involvement, higher recurrence rates, and shorter disease-free survival. ${ }^{45}$ Marked COX-2 expression was found in the cytoplasm of cells of the tumor invasive front and also in the cells of the surrounding stroma and vessels, indicating a putative role in tumor invasion and development of metastases. ${ }^{16,46}$ Another study demonstrated that COX-2 overexpression in OSCC was associated with higher radioresistance; tumor cells treated in vitro with a COX-2 inhibitor showed better response to radiotherapy. ${ }^{47}$ These findings can obviously have interesting and valuable prognostic and therapeutic implications.

Molecular markers. Cancer cells result from disruptions in circuits that regulate proliferation and homeostasis of normal cells. ${ }^{48,49}$ Although various genetic changes are associated with several types of disturbances and many types of cancers, there are 6 typical modifications in cellular physiology: self-sufficiency of growth signals, insensitivity to growth-inhibitor signals, evasion of apoptosis, unlimited replicative potential, ability to promote sustained angiogenesis, and capacity to invade surrounding tissues and metastasize. ${ }^{48}$

Several genetic aberrations have been identified in OSCC, most frequently in chromosomes 3, 9, 11, 13, and 17. Among others, the inactivation of tumorsuppressor genes such as p16 (9p21) and p53 (17p), the overexpression of oncogenes such as PRAD-1 (11q), and the alteration of genes involved in the metabolism of carcinogens or DNA repair seem to play a role in the carcinogenesis of OSCC. ${ }^{49}$ Moreover, most oral carcinomas are telomerase-activity positive. ${ }^{29,50}$ The study of these alterations is important for the characterization of cancer cells, with implications in the detection of individual and familial risk, noninvasive early diagnosis, tumor staging, therapy, and prognosis. ${ }^{51}$ Some of the most thoroughly studied genetic modifications implicated in the prognosis of OSCC are summarized as follows.

Oncogenes. Epidermal growth factor receptor (EGFR): EGFR proto-oncogene maps to 7p13-q22, and encodes a transmembrane protein whose activation by ligands such as epidermal growth factor or transforming growth factor alpha triggers a cascade of intracellular biochemical processes involved in cellular proliferation, differentiation, migration, and antiapoptotic pathways; it seems to play a significant role in cancer cell proliferation, survival, and mobility. Its overexpression is common in many malignancies, including breast, prostate, lung, and bladder cancers, correlating with poor prognosis. ${ }^{29,49,52,53}$ In OSCC it has been frequently associated with advanced $\mathrm{T}$ stage, diffuse tumor invasiveness, and high incidence of cervical node metastases. ${ }^{29}$ Its expression has also been correlated with lower histologic tumor differentiation. ${ }^{54}$ Recently published works emphasize 
EGFR as an anticancer therapeutic target in OSCC, with promising results both in vitro and in vivo. ${ }^{55,56}$ Research concerning cancer chemoprevention of head and neck cancer using EGFR tyrosine kinase inhibitors (gefitinib, erlotinib) is also in progress. 52

$c$-myc: Gene involved in the regulation of genetic expression and cell cycle. Its overexpression is associated with loss of differentiation in OSCC, although its correlation with survival is not clear. ${ }^{29}$

Cyclin D1: Proto-oncogene that regulates cell cycle; its product, CCND1, phosphorylates $R b$, promoting the transition $\mathrm{G} 1 \rightarrow \mathrm{S}$. Cyclin D1 activity is inhibited by several tumor-suppressor genes, including the subsequently discussed $p 16, p 21$, and $p 27$. The amplification and overexpression of this gene are independent prognosis factors in several tumors, including head and neck SCC. ${ }^{57,58}$ Increased expression of cyclin D1 is associated with the presence of regional nodal metastases, and advanced tumor stage. Therefore, it may be a useful prognostic indicator, although some authors find these data controversial. ${ }^{29,50,51}$

Cyclin A: Crucial for DNA synthesis in phase $\mathrm{S}$ and $\mathrm{G} 2 \rightarrow \mathrm{M}$ progression, its overexpression has been correlated with poorer prognosis in several human tumors. High cyclin A indices correlate with advanced disease stage, larger tumor volume, nodal metastases, and recurrence. It has been reported that patients with more than $15 \%$ cyclin $\mathrm{A}$-positive cells show a significantly shorter survival when compared with those presenting less than that value. ${ }^{59}$

Tumor-suppressor genes. p53: One of the most important genes influencing human carcinogenesis; protein p53 is involved in cell cycle control, apoptosis, and the preservation of genetic stability. In carcinomas, its expression is higher in those more undifferentiated, correlating with a more burdensome prognosis; yet some published works do not confirm these data, maybe partly because the mutations precede the clinicopathologic changes. ${ }^{29,50,51,60-62}$ p53 gene mutations may be better predictors of recurrence than the expression of the protein, and serum p53 levels may be more efficient prognosticators than its tissue immunodetection. ${ }^{51}$ The impact of $p 53$ in the prediction of tumor radiosensitivity has been investigated with contradictory results. $^{29,50,63}$ p53 is an attractive target for gene therapy; some experiments have been conducted using adenoviral vectors, and encouraging results have been achieved. $^{29}$

$R b$ : Its mutation or decrease of activity causes uncontrolled cellular proliferation. In OSCC the relation with prognosis is not well established. ${ }^{29}$ However, Takes et al. ${ }^{64}$ reported an association between loss of expression of gene $R b$ and higher probability of nodal metastases in OSCC. p16: Halts cell cycle progression at G1. Deletions of p16 seem to be crucial for the malignant progression, and deletions of 9p21 influence survival, recurrence rates, and the presence of nodal metastases. Allelic imbalance at 9p21 predicts poorer prognosis. ${ }^{29,51}$

p21 WAF1/CIP1: An inhibitor of cyclin-dependent kinases, arresting cell cycle progression. Protein p21 is a product of genes $W A F 1, C I P 1$, or $S D 11$. The expression of $\mathrm{p} 21^{\mathrm{WAF} 1 / \mathrm{CIP} 1}$ inversely correlates with parameter $\mathrm{T}$ and clinical staging but not with parameter $\mathrm{N}$, tumor differentiation, or apoptotic variables. Patients with tumors expressing higher values of $\mathrm{p} 21^{\mathrm{WAF} 1 / \mathrm{CIP} 1}$ have longer disease-specific survival. ${ }^{65}$

p2 $7^{\mathrm{kip} 1}$ : Inhibitor of cyclin-dependent kinases, hampering the transition $\mathrm{G} 1 \rightarrow \mathrm{S}$; its low expression has been correlated with worse prognosis in several human tumors, including OSCC. ${ }^{66}$

p34 ${ }^{\text {cdc2 }}$ : Cyclin-dependent kinase that regulates cellular entry into mitosis; it is a cell proliferation index. In $\mathrm{p} 34^{\mathrm{cdc} 2}$-positive tongue SCC a significantly lower survival has been found. ${ }^{67}$

Allelic imbalance (AI)/loss of heterozygosity ( $\mathrm{LOH})$. In OSCC, patients showing AI at 1 or more loci in 3p24$26,3 \mathrm{p} 13$, or $9 \mathrm{p} 21$ may have mortality rates 25 times higher. ${ }^{68}$ High fractional allelic loss correlates with higher recurrence and less survival. Evidence exists that AI at some specific pairs of loci is a better prognosticator than the TNM staging system. ${ }^{68}$ In a study of LOH at $2 \mathrm{q}, 3 \mathrm{p}$, and $21 \mathrm{q}$ it was shown that allelic loss in these regions is associated with the progression of OSCC and correlates with worse prognosis, particularly regarding 2q. ${ }^{69}$ The molecular study of these loci may help select patients who should undergo more aggressive therapies.

Ploidy. Abnormal DNA content has been associated with advanced stage OSCC and other markers of poor prognosis, such as lower degree of differentiation and lymph node metastasis. It appears to be an independent prognostic factor for relapse and death; it was found useful also as a valuable differential diagnosis marker for nondysplastic oral white patches or as predictor of occult nodal metastasis. ${ }^{70-72}$ However, debate has been maintained over this issue owing to the reported intratumoral heterogeneity of DNA ploidy, with some authors defending a homogeneous distribution of ploidy in the tumor maintained even in the metastasis (although ploidy has not been correlated with prognosis) ${ }^{73}$ and others reporting heterogeneity and thus limited application to predict prognosis. ${ }^{74}$ The study of DNA content of cells in the tumor invasive front, considered important to measure tumor aggressiveness (and therefore predict outcome), suggested an influence on disease-specific survival, especially if in conjunction with clinical findings. $^{75}$ 
Cell proliferation markers. Several methods have been used to assess cell proliferation. Their prognostic value is still a matter of debate, because different markers have been considered relevant to prognosis in some papers whereas markers of proliferation failed to correlate with the prognosis in other papers, a fact attributed to heterogeneity of series, different anatomic locations, or other differences in methodology. Apparently, no single method will be able to predict prognosis, but eventually a combination of static and dynamic parameters of cell cycle (eg, immunohistochemistry of Ki-67/MIB1 and silver staining of argyrophilic nucleolar organizer region-associated proteins) may prove to be a helpful and inexpensive prognostic factor. $^{29,76}$

Intercellular adhesion molecules. Intercellular adhesion molecules are important for tumor development, invasiveness, and appearance of metastases. Some alterations in expression and/or function are reported in OSCC, and those more frequently associated with OSCC prognosis concern E- and P-cadherins, catenins, and CD44. Several papers correlate poorer prognosis with primary tumor changes of CD44v9 phenotype, with lower expression of CD44v3, and especially with reduced expression of E-cadherin and P-cadherin. ${ }^{77-80}$ E-cadherin down-regulation was attributed to promoter hypermethylation. ${ }^{81}$ Additionally, nodal metastases were independently associated with decreased beta-catenin expression.

Human papillomavirus (HPV). There is escalating evidence of a causal association between HPV and OSCC, ${ }^{82-93}$ with several studies showing that HPV is associated with increased risk of oral cancer, independently of exposure to tobacco and alcohol. ${ }^{84,86,88,89}$ This association is valid for high-risk HPV, which comprises subtypes $16,18,33$, and 35 . HPV-16 may be responsible for more than $80 \%$ of HPV-positive OSCC. ${ }^{82,83,85-88,90,93}$ The virus can be detected in tissues or cells using several methods, namely, biochemical, immunologic, microscopic, and molecular. Polymerase chain reaction is considered the most sensitive assay. ${ }^{85,86}$

p53 remains the most commonly mutated gene in many common human cancers, but in a high proportion of cases lacking mutations its function is compromised by other mechanisms. ${ }^{83,84,92}$ Regarding HPV, this may occur via interaction of p53 with protein E6 encoded by the oncogenic HPV types, mainly HPV-16 and HPV-18, which results in increased ubiquitin-dependent proteolysis of $\mathrm{p} 53 .^{82,83,92-94}$ The expression of wild-type p53 in HPV-positive tumors contrasts with the higher frequency of p53 mutation in HPV-negative cases, and this fact seems to be associated with better prognosis in patients with HPV-positive OSSC. ${ }^{82,83,94}$ Recently published data on the prevalence of HPV infection in OSCC points to rates between $15 \%$ and $30 \%$, but this might be an underestimation; it may ascend to more than $50 \% .^{84,86,87,89,91}$ The disparity found in the published data has been associated with variations in collection of samples, the efficiency of the detection procedure, and geographic parameters. It is not well established how HPV infects the upper airway and oral cavity, but epidemiologic evidence suggests sexual transmission, ${ }^{82,93}$ because the prevalence of infection increases after the onset of sexual activity, although the presence of HPV in OSCC has not yet been robustly linked to sexual practices such as oral sex. ${ }^{82}$

The presence of HPV DNA in a significant fraction of OSCC raised the question of whether HPV tumor status affects the outcome of oral cancer. To date, the findings have been inconsistent, with some studies reporting no survival differences ${ }^{84,87,94}$ and others clearly stating a reduction in death risk among patients with HPVpositive tumors when compared with those with HPVnegative tumors. ${ }^{82,83,88,90-92}$ A large study conducted by Gillison et al. ${ }^{82}$ has shown that patients with HPVpositive tumors had a $60 \%$ reduction in risk of death from cancer and significantly improved disease-specific survival when compared patients with HPV-negative tumors. Schwartz et al. ${ }^{90}$ also found a strong association between the presence of HPV-16 DNA in OSCC and prolonged survival. These findings support the theory that HPV-positive OSSC may represent a distinct molecular, biologic, and clinical identity, supposedly associated in causal terms with HPV infection and possibly carrying better prognosis than HPV-negative cases. ${ }^{82,83,90}$

Miscellaneous. Uridine phosphorylase (UPase) is an enzyme that catalyzes the phosphorolysis of uridine to uracil. Its expression and activity are increased in solid tumors, including head and neck tumors. Positive UPase marking correlates well with lymphatic metastases, but not with tumor size or location, histologic differentiation, or global survival. ${ }^{95}$ Protein S100A4 (involved in the mobility of cancer cells) has been associated with strong tumor invasiveness and higher probability of nodal metastasis. ${ }^{96}$ The expression of the glucose transporter Glut-1 was studied in OSCC, as well as tumor glucose metabolism. High levels of both parameters correlated with a significantly shorter survival, ${ }^{97}$ which is consistent with the notion that tumors with aggressive biologic behavior present higher metabolic levels. Lymphocytic infiltration surrounding invasive carcinomas is composed mainly of T lymphocytes, and represents a true immune response. The prognosis seems better for marked infiltrations than for smaller ones. ${ }^{27,29}$ A strong association between OSCC autofluorescence (emitted by pigments of the porphyrin 
group) and categories $\mathrm{T}$ and $\mathrm{N}$ has been found; therefore, autofluorescence may be an indicator of tumor progression and, eventually, prognosis. ${ }^{98}$

\section{Treatment-related factors}

It is not our present intention whatsoever to evaluate the efficacy of the several therapeutic modalities used in OSCC. However, we should point out some issues related to the treatment of OSCC with likely influence on the outcome.

Cervical node dissection. Classically, the surgical procedure employed in the presence of noticeable cervical node metastases has been radical neck dissection (for details regarding cervical node classification see reference ${ }^{99}$ ). However, this procedure is a source of significant postoperative morbidity, namely shoulder dysfunction, which may be minimized using a 2-stage procedure. Furthermore, recently published work asserts that sparing 1 or both internal jugular veins is associated with a reduction in mortality rates, not endangering the prognosis. ${ }^{32}$ Selective neck dissection, highly dependent on the primitive tumor location, apparently achieves similar regional control and survival rates as those attained with more extensive neck dissections. $^{32}$ This approach may also serve staging purposes and assist the selection of patients for adjuvant therapy. Sentinel node detection, using lymphocyntigraphy or dye injection, may be beneficial in the choice of the type and extension of neck dissection, effectively decreasing the aggressiveness of surgical interventions. The method is apparently not difficult to implement and easily identifies the sentinel node. ${ }^{100,101}$ Ross et al. ${ }^{100}$ have established the sensitivity of the procedure as $94 \%$, when using the lymphocyntigraphy, the dye, and the full pathologic protocol.

Resection margin. A strong correlation has been demonstrated between a resection margin free of disease and higher survival rates, with longer time until recurrence of disease. ${ }^{11,31,35}$

\section{DISCUSSION}

Despite the attainments already achieved concerning OSCC diagnosis and therapy, mortality and morbidity rates are still exceedingly high, challenging the available methods of prognosis assessment and encouraging the search for new and better markers, namely, molecular markers that relate comprehensively with known alterations of tumor progression. The immense diversity found in the field of clinical oncology must be considered from 2 main perspectives: the biologic distinctiveness of each patient and the biologic distinctiveness of each malignancy. Currently, in practical terms, the factors with greater consensual influence on disease outcome include disease staging, extracapsular spread, tumor thickness, and resection margin free of disease. In the future, better results in clinical oncology appear to rely on improved understanding of tumor molecular biology.

A vast number of molecular markers have been correlated with OSCC outcome, illustrating the complex events leading to carcinogenesis and cancer progression. Furthermore, some of the proposed markers are frequently debated and sometimes results seem to contradict each other. Several factors may explain this situation, such as the small number of individuals included in each study or the heterogeneity of selected patients, which frequently differ in various features, notably tumor location. One other complexity is the possible intratumoral heterogeneity of the marker, for which multiple sampling of the tumor may be the key. Tumor invasive front analysis is gaining relevance because it might better reflect tumor-host interactions and consequently the aggressiveness and prognosis.

A multitude of factors are involved in prognosis, and probably no single marker can accurately predict the final results. Tumor progression is a multifactorial and multistep process; therefore multiple marker evaluation may logically be required to estimate the final results. Unfortunately, the widespread introduction of biologic markers into daily clinical practice has been slow and rather ineffective, hampering the completion of clinical studies to assess their real usefulness and facilitate their definitive implementation. In addition, the scattering of published data complicates the translation into the clinical setting.

Global RNA expression analysis can be achieved by DNA microarray technology, which has been used in various cancers, ${ }^{102}$ including oral cancer, ${ }^{103,104}$ to obtain gene expression profiles, associating them subsequently with clinical features. The potential of this method is vast, but one must not forget that cDNA microarray assays can only analyze the transcriptome, whereas biologic function is mediated mostly by proteins. RNA levels do not always correlate with protein levels and are not sensitive to post-translational modifications. Recently, proteomic methods such as 2-D gel electrophoresis and high-throughput mass spectrometry have been used to establish salivary proteome, and reliable information can be obtained through them. Multiple biomarker analysis can establish patterns which may be associated with the outcome. ${ }^{105,106}$ However, complex patterns may be difficult to discern by the human eye and mind, and bioinformatics algorithms will probably be useful. Proteomic analysis of whole body fluid protein components has been developed for the monitoring of health status and for early disease diagnosis and characterization. In addition, salivary biomarkers, relying on a supposed link between salivary proteins and systemic 
diseases, may be of value. Proteomic analysis of multiple markers present in saliva, a noninvasive and readily available method, may become in the future a powerful bedside technique. ${ }^{105-107}$

Conceivably, an upcoming all-inclusive molecular and clinical staging system will allow a more accurate selection of patients that should undergo more aggressive, specific, or individualized cancer therapy. We believe that further knowledge and subsequent application of the methods exposed above will definitely increase prognostic and therapeutic success, effectively decreasing morbidity and mortality rates associated with OSCC.

The authors are indebted to Carlos Oliveira, $\mathrm{MD}, \mathrm{PhD}$, and Fernando Regateiro, $\mathrm{MD}, \mathrm{PhD}$, for critical reading of the manuscript and valuable suggestions and comments. The authors also wish to thank Silvério Cabrita, $\mathrm{MD}, \mathrm{PhD}$, and Maria José Julião, MD, for the photomicrographs.

\section{REFERENCES}

1. Beenken SW, Urist MM. Head and neck tumors. In: Way LW, Doherty GM, editors. Current surgical diagnosis and treatment. 11th ed. New York: Lange Medical Books/McGraw-Hill; 2003. p. 282-97.

2. Coleman JJ, Sultan MR. Tumors of the head and neck. In: Schwartz SI, editor. Principles of surgery. 7th edition. New York: McGraw-Hill; 1999. p. 601-65.

3. World Health Organization. The World Oral Health Report 2003. Geneva: World Health Organization; 2003. p. 6-7.

4. Centers for Disease Control and Prevention. Preventing and controlling oral and pharyngeal cancer. Recommendations from a national strategic planning conference. MMWR 1998; 47(RR-14):1-12.

5. U.S. Department of Health and Human Services. Oral health in America: a report of the Surgeon General-executive summary. Rockville (MD): US Department of Health and Human Services, National Institute of Dental and Craniofacial Research, National Institutes of Health; 2000. p. 1-13.

6. La Vecchia C, Lucchini F, Negri E, Levi F. Trends in oral cancer mortality in Europe. Oral Oncol 2004;40:433-9.

7. Lo W-L, Kao S-Y, Chi L-Y, Wong Y-K, Chang RC-S. Outcomes of oral squamous cell carcinoma in Taiwan after surgical therapy: factors affecting survival. J Oral Maxillofac Surg 2003;61: 751-8.

8. O-charoenrat P, Pillai G, Patel S, Ficher C, Archer D, Eccles S, et al. Tumor thickness predicts cervical nodal metastases and survival in early oral tongue cancer. Oral Oncol 2003;39: 386-90.

9. Nguyen TV, Yueh B. Weight loss predicts mortality after recurrent oral cavity and oropharyngeal carcinomas. Cancer 2002; 95:553-62.

10. Leite ICG, Koifman S. Survival analysis in a sample of oral cancer patients at a reference hospital in Rio de Janeiro, Brazil. Oral Oncol 1998;34:347-52.

11. Al-Rajhi N, Khafaga Y, El-Husseiny J, Saleem M, Mourad W, Al-Otieschan A, et al. Early stage carcinoma of oral tongue: prognostic factors for local control and survival. Oral Oncol 2000;36:508-14.

12. Ribeiro KCB, Kowalski LP, Latorre MRDO. Perioperative complications, comorbidities, and survival in oral or oropharyngeal cancer. Arch Otolaryngol Head Neck Surg 2003;129:219-28.

13. Ribeiro KCB, Kowalski LP, Latorre MRDO. Impact of comorbidity, symptoms, and patients' characteristics on the prognosis of oral carcinomas. Arch Otolaryngol Head Neck Surg 2000; 126:1079-85.
14. Carvalho AL, Singh B, Spiro RH, Kowalski LP, Shah JP. Cancer of the oral cavity: a comparison between institutions in a developing and a developed nation. Head Neck 2004;26:31-8.

15. Hall SF, Groome PA, Rothwell D. The impact of comorbidity on the survival of patients with squamous cell carcinoma of the head and neck. Head Neck 2000;22:317-22.

16. Day GL, Blot WJ, Shore RE, McLaughlin JK, Austin DF, Greenberg RS, et al. Second cancers following oral and pharyngeal cancers: role of tobacco and alcohol. J Natl Cancer Inst 1994;86:131-7.

17. Silverman S Jr, Gorsky M, Greenspan D. Tobacco usage in patients with head and neck carcinomas: a follow-up study on habit changes and second primary oral/oropharyngeal cancers. J Am Dent Assoc 1983;106:33-5.

18. Deleyiannis FW-B, Thomas DB, Vaughan TL, Davis S. Alcoholism: independent predictor of survival in patients with head and neck cancer. J Natl Cancer Inst 1996;88:542-9.

19. Allison P, Locker D, Feine JS. The role of diagnostic delays in the prognosis of oral cancer: a review of the literature. Oral Oncol 1998;34:161-70.

20. Piccirillo JF, Lacy PD, Basu A, Spitznagel EL. Development of a new head and neck cancer-specific comorbidity index. Arch Otolaryngol Head Neck Surg 2002;128:1172-9.

21. Preciado DA, Matas A, Adams GL. Squamous cell carcinoma of the head and neck in solid organ transplant recipients. Head Neck 2002;24:319-25.

22. Whiteside TL. Immunobiology and immunotherapy of head and neck cancer. Curr Oncol Rep 2001;3:46-55.

23. Rosenberg SA, Yang JC, Restifo NP. Cancer immunotherapy: moving beyond current vaccines. Nat Med 2004;10:909-15.

24. Genden EM, Ferlito A, Bradley PJ, Rinaldo A, Scully C. Neck disease and distant metastases. Oral Oncol 2003;39:207-12.

25. Tiwari R. Squamous cell carcinoma of the superior gingivolabial sulcus. Oral Oncol 2000;36:461-5.

26. Gonzales-Moles MA, Esteban F, Rodriguez-Archilla A, RuizAvila I, Gonzales-Moles S. Importance of tumour thickness measurement in prognosis of tongue cancer. Oral Oncol 2002; 38:394-7.

27. Takes RP. Staging of the neck in patients with head and neck squamous cell cancer: Imaging techniques and biomarkers. Oral Oncol 2004;40:656-67.

28. Shpitzer T, Chaimoff M, Gal R, Stern Y, Feinmesser R, Segal $\mathrm{K}$. Tumor angiogenesis as a prognostic factor in early oral tongue cancer. Arch Otolaryngol Head Neck Surg 1996;122: 865-8.

29. Bettendorf O, Piffkò J, Bànkfalvi A. Prognostic and predictive factors in oral squamous cell cancer: important tools for planning individual therapy? Oral Oncol 2004;40:110-9.

30. Vicente JC, Herrero-Zapatero A, Fresno MF, López-Arranz JS. Expression of cyclin D1 and Ki-67 in squamous cell carcinoma of the oral cavity: clinicopathological and prognostic significance. Oral Oncol 2002;38:301-8.

31. Guerra MFM, Gías LN, Campo FR, Pérez JS. Marginal and segmental mandibulectomy in patients with oral cancer: a statistical analysis of 106 cases. J Oral Maxillofac Surg 2003; 61:1289-96.

32. Ferlito A, Rinaldo A, Robbins KT, Leemans CR, Shah JP, Shaha $\mathrm{AR}$, et al. Changing concepts in the surgical management of the cervical node metastasis. Oral Oncol 2003;39:429-35.

33. Greenberg JS, El Naggar AK, Mo V, Roberts D, Myers JN. Disparity in pathologic and clinical lymph node staging in oral tongue carcinoma. Implications for therapeutic decision making. Cancer 2003;98:508-15.

34. Shingaki S, Takada M, Sasai K, Bibi R, Kobayashi T, Nomura $\mathrm{T}$, et al. Impact of lymph node metastasis on the pattern of failure and survival in oral carcinomas. Am J Surg 2003;185: 278-84.

35. Woolgar JA, Rogers SN, Lowe D, Brown JS, Vaughan ED. Cervical lymph node metastasis in oral cancer: the importance of even microscopic extracapsular spread. Oral Oncol 2003; 39:130-7. 
36. Greenberg JS, Fowler R, Gomez J, Mo V, Roberts D, El Naggar $\mathrm{AK}$, et al. Extent of extracapsular spread. A critical prognosticator in oral tongue cancer. Cancer 2003;97:1464-70.

37. Kosunen A, Ropponen K, Kellokoski J, Pukkila M, Virtaniemi $\mathrm{J}$, Valtonen $\mathrm{H}$, et al. Reduced expression of hyaluronan is a strong indicator of poor survival in oral squamous cell carcinoma. Oral Oncol 2004;40:257-63.

38. Rahima B, Shingaki S, Nagata M, Saito C. Prognostic significance of perineural invasion in oral and oropharyngeal carcinoma. Oral Surg Oral Med Oral Pathol Oral Radiol Endod 2004;97:423-31.

39. Rodolico V, Barresi E, Di Lorenzo R, Leonardi V, Napoli P, Rappa F, et al. Lymph node metastasis in lower lip squamous cell carcinoma in relation to tumour size, histologic variables and p27 ${ }^{\text {Kip1 }}$ protein expression. Oral Oncol 2004;40:92-8.

40. Carmeliet P. Angiogenesis in health and disease. Nat Med 2003;9:653-60.

41. Hannen EJM, Riediger D. The quantification of angiogenesis in relation to metastasis in oral cancer: a review. Int J Oral Maxillofac Surg 2004;33:2-7.

42. Offersen BV, Borre M, Overgaard J. Quantification of angiogenesis as a prognostic marker in human carcinomas: a critical evaluation of histopathological methods for estimation of vascular density. Eur J Cancer 2003;39:881-90.

43. Shintani S, Li C, Ishikawa T, Mihara M, Nakashiro K, Hamakawa $\mathrm{H}$. Expression of vascular endothelial growth factor A, $\mathrm{B}, \mathrm{C}$, and $\mathrm{D}$ in oral squamous cell carcinoma. Oral Oncol 2004;40:13-20.

44. Uehara M, Sano K, Ikeda H, Sekine J, Irie A, Yokota T, et al. Expression of vascular endothelial growth factor and prognosis of oral squamous cell carcinoma. Oral Oncol 2004;40:321-5.

45. Itoh S, Matsui K, Furuta I, Takano Y. Immunohistochemical study on overexpression of cyclooxygenase-2 in squamous cell carcinoma of the oral cavity: its importance as a prognostic predictor. Oral Oncol 2003;39:829-35.

46. Thomas GT, Lewis MP, Speight PM. Matrix metalloproteinases and oral cancer. Oral Oncol 1999;35:227-33.

47. Terakado N, Shintani S, Yano J, Chunnan L, Mihara M, Nakashiro $\mathrm{K}$, et al. Overexpression of cyclooxygenase-2 is associated with radioresistance in oral squamous cell carcinoma. Oral Oncol 2004;40:383-9.

48. Hanahan D, Weinberg RA. The hallmarks of cancer. Cell 2000; 100:57-70.

49. Scully C, Field JK, Tanzawa H. Genetic aberrations in oral or head and neck squamous cell carcinoma (SCCHN): 1. Carcinogen metabolism, DNA repair and cell cycle control. Oral Oncol 2000;36:256-63.

50. Scully C, Field JK, Tanzawa H. Genetic aberrations in oral or head and neck squamous cell carcinoma 2: chromosomal aberrations. Oral Oncol 2000;36:311-27.

51. Scully C, Field JK, Tanzawa H. Genetic aberrations in oral or head and neck squamous cell carcinoma 3: clinico-pathological applications. Oral Oncol 2000;36:404-13.

52. Rhee JC, Khuri FR, Shin DM. Advances in chemoprevention of head and neck cancer. Oncologist 2004;9:302-11.

53. Grünwald V, Hidalgo M. Developing inhibitors of the epidermal growth factor receptor for cancer treatment. J Natl Cancer Inst 2003;95:851-67.

54. Ulanovski D, Stern Y, Roizman P, Shpitzer T, Popovter A, Feinmesser R. Expression of EGFR and Cerb-B2 as prognostic factors in cancer of the tongue. Oral Oncol 2004;40: 532-7.

55. Shintani S, Li C, Mihara M, Yano J, Terakado N, Nakashiro K, et al. Gefinitib ('Iressa', ZD1839), an epidermal growth factor receptor tyrosine kinase inhibitor, up-regulates $\mathrm{p} 27^{\mathrm{KIP} 1}$ and induces G1 arrest in oral squamous cell carcinoma cell lines. Oral Oncol 2004;40:43-51.

56. Myers JN, Holsinger FC, Bekele BN, Li E, Jasser SA, Killion $\mathrm{JJ}$, et al. Targeted molecular therapy for oral cancer with epidermal growth factor receptor blockade. Arch Otolaryngol Head Neck Surg 2002;128:875-9.
57. Miyamoto R, Uzawa N, Nagaoka S, Hirata Y, Amagasa T. Prognostic significance of cyclin D1 amplification and overexpression in oral squamous cell carcinomas. Oral Oncol 2003; 39:610-8.

58. Schneeberger C, Eder S, Swoboda H, Ullrich R, Zeillinger R. A differential PCR system for the determination of CCNDI (cyclin D1) gene amplification in head and neck squamous cell carcinomas. Oral Oncol 1998;34:257-60.

59. Chen H-M, Kuo MY-P, Lin K-H, Lin C-Y, Chiang C-P. Expression of cyclin A is related to progression of oral squamous cell carcinoma in Taiwan. Oral Oncol 2003;39:476-82.

60. Yamazaki Y, Chiba I, Hirai A, Sugiura C, Notani K, Kashiwazaki $\mathrm{H}$, et al. Specific p53 mutations predict poor prognosis in oral squamous cell carcinoma. Oral Oncol 2003;39:163-9.

61. Huang M-F, Chang Y-C, Liao P-S, Huang T-H, Tsay C-H, Chou M-Y. Loss of heterozigosity of $p 53$ gene of oral cancer detected by exfoliative cytology. Oral Oncol 1999;35:296-301.

62. Atula S, Grénman R, Laippala P, Syrjänen S. Cancer of the tongue in patients younger than 40 years. A distinct entity? Arch Otolaryngol Head Neck Surg 1996;122:1313-9.

63. Dijkema IM, Struikmans H, Dullens HFJ, Kal HB, van der Tweel I, Batterman JJ. Influence of $p 53$ and $b c l-2$ on proliferative activity and treatment outcome in head and neck cancer patients. Oral Oncol 2000;36:54-60.

64. Takes RP, de Jong RJB, Alles MJRC, Meeuwis CA, Marres HAM, Knegt PPM, et al. Markers for nodal metastases in head and neck squamous cell cancer. Arch Otolaryngol Head Neck Surg 2002;128:512-8.

65. Xie X, Clausen OPF, Boysen M. Prognostic significance of $\mathrm{p} 21^{\mathrm{WAF} / \mathrm{CIP} 1}$ expression in tongue squamous cell carcinomas. Arch Otolaryngol Head Neck Surg 2002;128:897-902.

66. Kuo MY-P, Hsu H-Y, Kok S-H, Kuo R-C, Yang H, Hahn L-J, et al. Prognostic role of $\mathrm{p} 27^{\mathrm{Kip} 1}$ expression in oral squamous cell carcinoma in Taiwan. Oral Oncol 2002;38:172-8.

67. Wada S, Yue L, Furuta I. Prognostic significance of $\mathrm{p} 34^{\mathrm{cdc} 2}$ expression in tongue squamous cell carcinoma. Oral Oncol 2004;40:164-9.

68. Partridge M, Emilion G, Pateromichelakis S, A'Hern R, Lee G, Phillips E, et al. The prognostic significance of allelic imbalance at key chromosomal loci in oral cancer. $\mathrm{Br} \mathrm{J}$ Cancer 1999;79:1821-7.

69. Yamamoto N, Mizoe J, Numasawa $H$, Tsujii $H$, Shibahara $T$, Noma H. Allelic loss on chromosomes 2q, 3p and 21q: possibly a poor prognostic factor in oral squamous cell carcinoma. Oral Oncol 2003;39:796-805.

70. Bueno PR, Gias LN, Delgado RG, Cebollada JD, González FJD. Tumor DNA content as a prognostic indicator in squamous cell carcinoma of the oral cavity and tongue base. Head Neck 1998;20:232-9.

71. Sudb $\varnothing$ J, Ried T, Bryne M, Kildal W, Danielsen H, Reith A. Abnormal DNA content predicts the occurrence in carcinomas in nondysplastic oral white patches. Oral Oncol 2001; 37:558-65.

72. Byers RM, El Naggar AK, Lee Y-Y, Rao B, Fornage B, Terry NHA, et al. Can we detect or predict the presence of occult nodal metastases in patients with squamous carcinoma of the oral tongue? Head Neck 1998;20:138-44.

73. Baretton G, Li X, Stoll C, Fischer-Brandies E, Schmidt M, Lohrs U. Prognostic significance of DNA ploidy in oral squamous cell carcinomas. A retrospective flow and image cytometric study with comparison of DNA ploidy in excisional biopsy specimens and resection specimens, primary tumors, and lymph node metastases. Oral Surg Oral Med Oral Path Oral Radiol Endod 1995;79:68-76.

74. Diwakar N, Sperandio M, Sherriff M, Brown A, Odell EW. Heterogeneity, histological features and DNA ploidy in oral carcinoma by image-based analysis. Oral Oncol 2005;41:416-22.

75. Noguchi M, Kinjyo H, Kohama GI, Nakamori K. Invasive fron in oral squamous cell carcinoma: image and flow cytometric analysis with clinicopathologic correlation. Oral Surg Oral Med Oral Pathol Oral Radiol Endod 2002;93:682-7. 
76. Pich A, Chiusa L, Navone R. Prognostic relevance of cell proliferation in head and neck tumors. Ann Oncol 2004;15:1319-29.

77. Bánkfalvi A, Krassort M, Buchwalow IB, Végh A, Felszeghy E, Piffkó J. Gains and losses of adhesion molecules (CD44, E-cadherin, and beta-catenin) during oral carcinogenesis and tumour progression. J Pathol 2002;198:343-51.

78. Chow V, Yuen APW, Lam KY, Tsao GSW, Ho WK, Wei WI. A comparative study of the clinicopathological significance of E-cadherin and catenins (alpha, beta, gamma) expression in the surgical management of oral tongue carcinoma. J Cancer Res Clin Oncol 2001;127:59-63.

79. Muñoz-Guerra MF, Marazuela EG, Fernandez-Contreras ME, Gamallo C. P-cadherin expression reduced in squamous cell carcinoma of the oral cavity: an indicator of poor prognosis. Cancer 2005;103:960-9.

80. Bánkfalvi A, Krassort M, Végh A, Felszeghy E, Piffkó J. Deranged expression of the E-cadherin/beta-catenin complex and the epidermal growth factor receptor in the clinical evolution and progression of oral squamous cell carcinomas. J Oral Pathol Med 2002;31:450-7.

81. Chang HW, Chow V, Lam KY, Wei WI, Yuen APW. Loss of Ecadherin expression resulting from promoter hypermethylation in oral tongue carcinoma and its prognostic significance. Cancer 2002;94:386-92

82. Gillison ML, Koch WM, Capone RB, Spafford M, Westra WH, $\mathrm{Wu} \mathrm{L}$, et al. Evidence for a causal association between human papillomavirus and a subset of head and neck cancers. J Natl Cancer Inst 2000;92:709-20.

83. Chiba I, Shindoh M, Yasuda M, Yamazaki Y, Amemiya A, Sato $\mathrm{Y}$, et al. Mutations in the p53 gene and human papillomavirus infection as significant prognostic factors in squamous cell carcinomas of the oral cavity. Oncogene 1996;12:1663-8.

84. Báez A, Almodóvar JI, Cantor A, Celestin F, Cruz-Cruz L, Fonseca S, et al. High frequency of HPV16-associated head and neck squamous cell carcinoma in the Puerto Rican population. Head Neck 2004;26:778-84.

85. Kreimer AR, Clifford GM, Snijders PJF, Castellsagué X, Meijer CJLM, Pawlita M, et al. HPV16 semiquantitative viral load and serologic biomarkers in oral and oropharyngeal squamous cell carcinomas. Int J Cancer 2005;115:329-32.

86. Miller CS, Johnstone BM. Human papillomavirus as a risk factor for oral squamous cell carcinoma: a meta-analysis, 19821997. Oral Surg Oral Med Oral Pathol Oral Radiol Endod 2001;91:622-35.

87. Paz IB, Cook N, Odom-Maryon T, Xie Y, Wilczynski SP. Human papillomavirus (HPV) in head and neck cancer. An association of HPV 16 with squamous cell carcinoma of Waldeyer's tonsillar ring. Cancer 1997;79:595-604.

88. Syrjänen S. Human papillomavirus (HPV) in head and neck cancer. J Clin Virol 2005;32S:S59-66.

89. Zhang Z-y, Sdek P, Cao J, Chen W-t. Human papillomavirus type 16 and 18 DNA in oral squamous cell carcinoma and normal mucosa. Int J Oral Maxillofac Surg 2004;33:71-4.

90. Schwartz SR, Yueh B, McDougall JK, Daling JR, Schwartz SM. Human papillomavirus infection and survival in oral squamous cell cancer: A population-based study. Otolaryngol Head Neck Surg 2001;125:1-9.

91. Ritchie JM, Smith EM, Summersgill KF, Hoffman HT, Wang D, Klussmann JP, et al. Human papillomavirus infection as a prognostic factor in carcinomas of the oral cavity and oropharynx. Int J Cancer 2003;104:336-44.

92. Gascoa M, Crookb T. The p53 network in head and neck cancer. Oral Oncol 2003;39:222-31.
93. Mork J, Lie AK, Glattre E, Hallmans G, Jellum E, Koskela P, et al. Human papillomavirus infection as a risk factor for squamous-cell carcinoma of the head and neck. $\mathrm{N}$ Engl J Med 2001;344:1125-31.

94. Pintos J, Franco EL, Black MJ, Bergeron J, Arella M. Human papillomavirus and prognoses of patients with cancers of the upper aerodigestive tract. Cancer 1999;85:1903-9.

95. Miyashita H, Takebayashi Y, Eliason JF, Fujimori F, Nitta Y, Sato A, et al. Uridine phosphorylase is a potential prognostic factor in patients with oral squamous cell carcinoma. Cancer 2002;94:2959-66.

96. Moriyama-Kita M, Endo Y, Yonemura Y, Heizmann CW, Schäfer BW, Sasaki T, et al. Correlation of S100A4 expression with invasion and metastasis in oral squamous cell carcinoma. Oral Oncol 2004;40:496-500.

97. Kunkel M, Reichert TE, Benz P, Lehr H-A, Jeong J-H, Wieand $\mathrm{S}$, et al. Overexpression of Glut-1 and increased glucose metabolism in tumors are associated with a poor prognosis in patients with oral squamous cell carcinoma. Cancer 2003;97:1015-24.

98. Onizawa K, Okamura N, Saginoya H, Yoshida H. Characterization of autofluorescence in oral squamous cell carcinoma. Oral Oncol 2003;39:150-6.

99. Som PM, Curtin HD, Mancuso AA. An imaging-based classification for the cervical nodes designed as an adjunct to recent clinically based nodal classifications. Arch Otolaryngol Head Neck Surg 1999;125:388-96.

100. Ross G, Shoaib T, Soutar DS, Camilleri IG, Gray HW, Bessent $\mathrm{RG}$, et al. The use of sentinel node biopsy to upstage the clinically N0 neck in head and neck cancer. Arch Otolaryngol Head Neck Surg 2002;128:1287-91.

101. Taylor RJ, Wahl RL, Sharma PK, Bradford CR, Terrell JE, Teknos TN, et al. Sentinel node localization in oral cavity and oropharynx squamous cell cancer. Arch Otolaryngol Head Neck Surg 2001;127:970-4.

102. Aitman TJ. DNA microarrays in medical practice. BMJ 2001; 323:611-5.

103. Méndez E, Cheng C, Farwell DG, Ricks S, Agoff SN, Futran ND, et al. Transcriptional expression profiles of oral squamous cell carcinomas. Cancer 2002;95:1482-94.

104. Schmalbach CE, Chepeha DB, Giordano TJ, Rubin MA, Teknos $\mathrm{TN}$, Bradford CR, et al. Molecular profiling and the identification of genes associated with metastatic oral cavity/pharynx squamous cell carcinoma. Arch Otolaryngol Head Neck Surg 2004;130:295-302.

105. Vitorino R, Lobo MJC, Ferrer-Correira AJ, Dubin JR, Tomer $\mathrm{KB}$, Domingues PM, et al. Identification of human whole saliva protein components using proteomics. Proteomics 2004;4: $1109-15$.

106. Hu S, Xie Y, Ramachandran P, Loo RRO, Li Y, Loo JA, et al Large-scale identification of proteins in human salivary proteome by liquid chromatography/mass spectrometry and 2dimensional gel electrophoresis-mass spectrometry. Proteomics 2005;5:1714-28.

107. Petricoin EF, Liotta LA. Proteomic analysis at the bedside: early detection of cancer. Trends Biotechnol 2002;20:S30-4.

Reprint requests:

João Massano, MD

Lages Cima 9-A

3040-194 Coimbra

Portugal

joaomassano@huc.min-saude.pt 